Research Article

\title{
Evaluating the Academic Performance of K-12 Students in the Philippines: A Standardized Evaluation Approach
}

\author{
Porferio M. Almerino Jr. $\mathbb{D}^{1},{ }^{1}$ Lanndon A. Ocampo $\mathbb{D}^{2,3}$ Dharyll Prince M. Abellana ${ }^{2},{ }^{2}$ \\ Jana Gloria F. Almerino $\mathbb{D},{ }^{4}$ Irene O. Mamites $\mathbb{D},{ }^{5}$ Lilibeth C. Pinili $\mathbb{D},{ }^{6}$ \\ Janine Joy L. Tenerife $\mathbb{D}^{6}{ }^{6}$ Regina E. Sitoy $\mathbb{D}^{7}{ }^{7}$ Limuel J. Abelgas $\mathbb{D}^{7}$, \\ and Emerson D. Peteros $\mathbb{D D}^{1}$ \\ ${ }^{1}$ Mathematics and Science Area, College of Education, Cebu Technological University, Corner M.J. Cuenco Ave. \& R. Palma St., \\ Cebu City 6000, Philippines \\ ${ }^{2}$ Department of Industrial Engineering, Cebu Technological University, Corner M.J. Cuenco Ave. \& R. Palma St., \\ Cebu City 6000, Philippines \\ ${ }^{3}$ Graduate School, Cebu Technological University, Corner M.J. Cuenco Ave. \& R. Palma St., Cebu City 6000, Philippines \\ ${ }^{4}$ Human Resource Management Office, Cebu Technological University, Corner M.J. Cuenco Ave. \& R. Palma St., Cebu City 6000, \\ Philippines \\ ${ }^{5}$ Professional Education Area, College of Education, Cebu Technological University, Corner M.J. Cuenco Ave. \& R. Palma St., \\ Cebu City 6000, Philippines \\ ${ }^{6}$ Special Education Area, College of Education, Cebu Technological University, Corner M.J. Cuenco Ave. \& R. Palma St., \\ Cebu City 6000, Philippines \\ ${ }^{7}$ Social Studies, Values Education, English \& Filipino Area, College of Education, Cebu Technological University, \\ Corner M.J. Cuenco Ave. \& R. Palma St., Cebu City 6000, Philippines
}

Correspondence should be addressed to Lanndon A. Ocampo; lanndonocampo@gmail.com

Received 11 March 2020; Revised 17 August 2020; Accepted 29 September 2020; Published 19 October 2020

Academic Editor: Haoran Xie

Copyright (C) 2020 Porferio M. Almerino et al. This is an open access article distributed under the Creative Commons Attribution License, which permits unrestricted use, distribution, and reproduction in any medium, provided the original work is properly cited.

With growing technological advancements, demands for the industry with skilled and equipped workforce are proportionately rising. While this match between curricular offerings in academia and needs in the industry has been addressed in many countries across the globe through initiatives such as the K-12 educational system, some countries like the Philippines have only started its adoption. In the Philippines' early adoption of the K-12 educational system, several concerns have been raised regarding its implementation, mainly, the mismatch between coursework offered in Philippine K-12 educational institutions with industry demands. With such outcomes, it is necessary to determine the status of the K-12 educational system in the Philippines. This paper attempts to shed light on such concerns by evaluating the performance of the K-12 students using a standardized approach. The Scholastic Abilities Test for Adults, a standardized test for measuring the academic competence of adults, is used in this study to measure scholastic abilities. The descriptive analyses made in this paper may aid in the development of more robust strategy frameworks for positioning the current K-12 educational system to global and industry demands. Moreover, the results obtained in this study would aid stakeholders in overseeing strategies that would address current gaps in the K-12 educational system of the country. 


\section{Introduction}

Before the transition to the K-12 educational curriculum, the basic education in the Philippines consists of ten (10) years of study: six (6) years in elementary education and four (4) years in secondary education [1]. However, with the collective movement of other countries towards globalization, the Philippines has undertaken major educational reforms that transition and shift its 10 -year basic education into the $\mathrm{K}-12$ curriculum [1]. K-12 is an educational program in the United States (US) from kindergarten to grade 12 that indicates the range of years of supported primary and secondary education [2]. It has been adopted by many educational institutions across the globe such as Afghanistan [3], Australia [4], Canada [5], China [6], South Korea [7], and Turkey [8]. Several goals have been set by the government associated with the implementation of the K-12 curriculum as follows: (i) increase students' preparation for higher education, (ii) equip students' with eligibility for entering domestic and overseas higher educational institutions, and (iii) facilitate students' immediate employability upon graduation [9].

Despite the promising goals set by the Philippine government, several issues have spurred with the reform's implementation. For instance, Rivera [10] and Barrot [11] found misalignments between established learning pedagogies with the expected outcomes of the K-12 curriculum guidelines of the Philippines. Likewise, Trance and Trance [12] revealed a mismatch between the perceptions of teachers and students with the set expectations of the K-12 curriculum in the country. Moreover, Relucio and Palaoag [13] found an overall negative response between multiple K-12 curriculum stakeholders (e.g., teachers, students, and parents) regarding the implementation of the K-12 curriculum in the Philippines. These drawbacks suggest the streamlining of the K-12 curriculum in the Philippines by reviewing its current guidelines.

Despite the need to streamline the K-12 curriculum guidelines in the Philippines, the task has been difficult due to the limited number of studies in the literature regarding its status. While few in numbers, most of the works in the literature focused on identifying misalignments of learning outcomes and perception of stakeholders. However, none of the works provided insights about the performance of the K-12 students. Relevant works in the literature (e.g., [14-16]) maintain that students' performance provides a direct method of measuring the successful implementation of an educational program. With a limited number of studies focusing on measuring student performance of K-12 students in the country, a significant gap in the current literature remains unaddressed. Moreover, with the limited attention provided by scholars in the literature regarding the K-12 transition in the country, formulating more robust strategies and initiatives may become a significant impediment for stakeholders in the country. To address this gap, this paper provides an assessment of the K-12 curriculum's status in the country by evaluating the academic performance of recent K-12 graduates in the Philippines.

A case study in Cebu (Philippines), one of the major metropolitan areas in the country, is performed. Three major cities in Cebu are considered, namely, Cebu City, Lapu-Lapu City, and Mandaue City due to their relatively high number of K-12 students. The Scholastic Abilities Test for Adults (SATA) is used as the standardized instrument for the assessment. SATA is a standardized test that measures the scholastic competence of persons from the ages of 16 through 70 [17]. The SATA's aptitude and achievement components can provide an aptitude-achievement discrepancy analysis [17]. In this paper, the SATA is used to measure the scholastic abilities of K-12 students in Science, Technology, Engineering, and Mathematics (STEM), Accountancy Business and Management (ABM), Humanities and Social Sciences (HUMSS), General Academic Strand (GAS), and Technical, Vocational, Livelihood (TVL), using six subtests: (i) nonverbal reasoning (NV), (ii) quantitative reasoning (QR), (iii) reading vocabulary (RV), (iv) reading comprehension (RC), (v) mathematical capacity (MC), and (vi) mathematical applications (MA).

The results will enable the determination of a potential gap of the students' performance in each subtest. Such findings would serve as performance indicators for stakeholders regarding the status of the K-12 curriculum through the competencies of recent K-12 graduates. Moreover, the results would help shed light on the formulation of strategies needed in the alignment of the students' competencies towards the expected outcomes of the K-12 program. With minimal information regarding the performance of Filipino $\mathrm{K}-12$ graduates in the literature, the study would be significant as it is the first to conduct a performance evaluation of K-12 students using SATA in the Philippines. As such, the paper may be used as a benchmark for the formulation of policies and initiatives regarding the K-12 curriculum in the country. This paper is organized as follows: Section 2 presents comprehensive literature that comprises relevant works of the K-12 educational system. Section 3 presents the methodology. Section 4 discusses the results obtained in the study as well as their managerial implications. Finally, Section 5 presents the conclusions arrived in the paper as well as the potential future directions.

\section{Literature Review}

2.1. Overview of Basic Education in the Philippines. Before the transition to the K-12 educational curriculum, the basic education in the Philippines consists of ten (10) years of study: six (6) years in elementary education and four (4) years in secondary education [1]. The mismatch between the Philippines' basic education system with other countries adopting at least 12 years of basic education is attributed to several political, social, and economic pressures that affect the Philippine atmosphere since the Spanish colonization and, later, the American occupation [1]. This review does not go in depth with this topic for brevity; instead, the readers are referred to Adarlo and Jackson [1] for a comprehensive discussion. Every year, the Department of Education (DepEd), the country's agency on basic education, produces key statistics on the performance and internal efficiency of the basic education sector [18]. The agency reports that the overall performance of representative participants in the 
Programme for International Student Assessment (PISA, 2018) significantly fell behind from its neighboring ASEAN countries in terms of reading, mathematical, and scientific literacy [19]. In fact, in all three categories, the Philippines ranked last among the participating countries, such as Singapore, Malaysia, Brunei, Thailand, and Indonesia [19]. Previous studies such as Adarlo and Jackson [1], Mullis et al. [20], Martin et al. [21], Mullis et al. [22], and Martin et al. [23] have also shown the same trend for the country in that it scored an overall performance that is significantly below the international average in the 1999 and 2003 Trends in International Mathematics and Science Study.

Several issues have also been known in association with the low performance of the Philippines' basic education system, such as a significant proportion of out-of-school children [18]. Albert [18] maintains that the issue of out-ofschool children in the Philippines is associated with psychological, health, and economic factors. As such, the paper reports that a significant $36 \%$ and $44.1 \%$ of students reported a "lack of personal interest" as a reason for not attending school in primary and secondary levels, respectively. Likewise, a glaring $34.7 \%$ and $12.4 \%$ of students reported "illness or disability" as a reason for not attending school in primary and secondary levels, respectively. Moreover, $14.1 \%$ and $29.4 \%$ reported "high cost of education" as a reason for not attending school in primary and secondary levels, respectively. With basic education's significant role in securing a more prepared workforce, findings in the literature imply that the Philippine government would need to develop a holistic strategy in addressing the declining proportion of school attendance in the country.

Aside from the issue of out-of-school children in the country, concerns such as incompatibility with the movement towards globalization have posed a challenge for the basic education curriculum of the country. An analysis by Okabe [9] reveals that the 10-year basic education system posed several pedagogical and socioeconomic problems. For one, congested curricula (i.e., cramming courses into their curricula) are exhibited by many schools due to the pressure of fulfilling mandatory educational requirements. Likewise, due to the lower number of years in basic education as compared to countries having at least 12 years of basic education, Filipino basic education graduates (without further training) are considered underqualified for many overseas jobs. Moreover, with only a few years in basic education, graduates are often under the legal working age (18 years old) and become ineligible in jobs both domestic and overseas. With many issues surrounding the 10-year basic education curriculum of the country, the government is urged to develop policies and initiatives to address such concerns. In 2013, a major reform known as the "K-12 program" was enacted into law in the country with the expectation to help overcome these issues $[1,9,24]$.

2.2. The Transition to the K-12 System in the Philippines. The "K-12 program" is a comprehensive reform of the Philippines' basic education [1, 9, 19]. Through this reform, the Philippines is making efforts to catch up with global standards [9]. With changes in the structure, curricula, and philosophy of the education system, vast improvements with the previous 10-year basic education are anticipated. The key points addressed by the policy are preparation for higher education, eligibility for entering domestic and overseas higher educational institutions, and immediate employability upon graduation [9]. In the current literature, few scholars have worked on determining the status of the K-12 implementation in the Philippines. For instance, Rivera [10] provided an in-depth assessment of the K-12 curriculum in the Philippines by identifying the misalignment of teaching pedagogies. The study finds that a thorough review of the curriculum's content is needed for the development of more robust pedagogies. Trance and Trance [12] examined various accounts of teachers and students to gain an understanding of how they approach the K-12 curriculum. The study found a mismatch between the perception of students and teachers with the set of expectations of the program.

A similar finding was revealed by Barrot (2018) regarding the new English curriculum in that it is misaligned with the traditional language teaching and learning principles. As such, Barrot (2018) maintains that the new K-12 curriculum needs to improve its specificity, internal coherence, and integration of some essential principles of $21^{\text {st }}$ century learning and language teaching. Moreover, Relucio and Palaoag [13] found using a sentiment analysis of social media posts from students that the K-12 curriculum has received an overall negative response from students. The study by Relucio and Palaoag [13] may lead towards answering why resistance from multiple stakeholders (e.g., students, parents, and teachers) surfaces during its implementation. While the goals of the reform are promising, findings in the literature suggest that the government and policymakers need to streamline further and review the K-12 curriculum if the successful implementation is targeted in a reasonable time frame.

In the current literature, several learning initiatives have been proposed to enhance the learning of students across the globe. For instance, Krouska et al. [25] studied how new technological advances, such as social networks, integrate with pedagogical processes and learning styles. A more in-depth review of social networks-based learning systems is provided by Krouska et al. [26]. Troussas et al. [27] explored the roles of collaboration and fuzzy-modeled personalization for mobile game-based learning in education. Likewise, Troussas et al. [28] studied how adaptive grain-size delivery of the learning material helps render students achieve learning outcomes. Moreover, Krouska et al. [29] evaluated several learning management systems (e.g., Schoology, Moodle, and ATutor). They provided a comparative analysis to determine how they facilitate the development of e-learning environments with social features. These works in the literature offer useful insights into the development of learning initiatives during the K-12 transition in the Philippines. In the Philippine context, few papers have explored the role of new technology, such as e-learning, in facilitating the success of the K-12 curriculum. For instance, Nuncio et al. [30] conducted an e-learning outreach program for public schools in the Philippines. They found that the program improved the skills and knowledge of 
the participants, as well as developed a strong positive attitude towards e-learning outreach program.

On the contrary, Espiritu and Budhrani [31] revealed in an analysis of the challenges of the K-12 curriculum using multiple stakeholders' perspectives that learning initiatives (e.g., e-learning) have not been very effective in its current setup about facilitating the successful implementation of K-12 in the country. A similar result was found by Castillo [32] in studying ICT integration in Philippine public schools. Due to contradictory results in the current literature with regard to the role of new learning initiatives in facilitating successful K-12 implementation, it would be difficult for both scholars and stakeholders to evaluate the overall performance of the program in the country. Moreover, road mapping of future strategies may also be compromised due to the lack of compelling evidence regarding the performance of the K-12 curriculum in the country. Such a gap in the literature can be addressed by giving attention to the development and use of frameworks that can evaluate the status and performance of the K-12 curriculum in the country.

2.3. Measuring Educational Performance. In relevant domains, the implementation of policies, strategies, and other initiatives are evaluated using performance evaluation methods. Similarly, in education, the effectiveness of introduced programs is reviewed in the same way. For instance, Tam [33] proposed an indicator system for evaluating academic performance from a quality management perspective. Such proposal is consistent with the findings of Johnes and Taylor [34], which implies that educational institutions be evaluated using the information on (i) the outputs aimed to be produced, (ii) inputs needed to produce the outputs, (iii) quantitative measurements of each input and output, and (iv) technical relationship between inputs and outputs. In the current literature, another method for measuring effectiveness in education is by determining the effectiveness score, which is the difference between actual and predicted graduation rates [35]. Horn et al. [35] showed the method's validity by examining the measurement properties of effectiveness scores derived from regression residuals. Moreover, Srisakda et al. [36] developed an indicator system of learner's key competencies. Such an indicator system measures students' communication, thinking, problem-solving, applying life skills, and technological application capabilities.

While indicator systems have been useful in some applications, Man et al. [37] argued that indicator systems conceal gaps in the quality of education. Although the study was constrained to the Malaysian basic educational system, the paper showed that basic education indicators do not always translate into excellent performance in international assessments such as Trends in International Mathematics and Science Study (TIMSS). Thus, using other techniques may be useful in different applications. Another method adopted in the current literature concerns the use of descriptive analysis techniques. For example, Junio-Sabio et al. [38] used a descriptive analysis of the average score of elementary students in the Philippines to determine if learning outcomes per grade level increased. Moreover, some studies use inferential statistical techniques such as hypothesis tests in making comparisons between different factors. For instance, Bonsu [39] used a combination of the analysis and variance and $t$-test for comparing the performance of private and public secondary schools in Ghana.

Aside from indicator systems, descriptive analysis, and inferential techniques, skills/abilities tests are also prevalent in the basic education literature for measuring the academic performance of students. For instance, Bietenbeck et al. [16] measured the literacy and numeracy of basic education students in East Africa. The literacy test assessed four competencies in the order of increasing difficulty: (1) recognition of letters, (2) recognition of words, (3) reading a paragraph, and (4) reading a short story. Similarly, the numeracy test assessed (1) counting, (2) recognition of numbers, (3) rank ordering of numbers, (4) addition, (5) subtraction, and (6) multiplication [16]. Tseng et al. [15] developed a standardized seventh-grade English (L2) reading-literacy sample task and collected student work and feedback from participating teachers and students. The reading task was scenario-based and required that students search for missing pets [15].

A study by Badger and Mellanby [14] developed VES$\mathrm{PARCH}$, an online group test of verbal and spatial reasoning, to measure basic ability (or fluid intelligence) among basic education students in the UK. The study finds that comparison of VESPARCH scores with school attainment measures allows identification of those students who are underachieving academically relative to their potential [14]. In this regard, Badger and Mellanby [14] maintained that VESPARCH could be used alongside current school tests to ensure targeted teaching and encouragement for every student. In the US, the American College Test (ACT) and Scholastic Aptitude Test (SAT) scores have been part of the admission requirements for many undergraduate educational programs [40-42]. In summary, the scholastic performance of students in basic education programs is assessed using several dimensions: indicator systems, comparative tests (descriptive and inferential), and standardized tests, among others.

\section{Methodology}

3.1. Case Background. In 2013, the Philippines underwent a major reform in its education system through the implementation of the K-12 curriculum. Such an implementation extends the ten years of basic education in the country to 12 years. The Department of Education (DepEd) in the Philippines revealed that the new curriculum includes one year of mandatory kindergarten, six years of elementary education, four years of junior high school (grades 7 to 10), and two years of senior high school (grades 11 to 12). With spurring concerns such as misalignment of expectation and learning outcomes, mismatch in perceptions of stakeholders, and negative response of multiple stakeholders regarding the K-12 curriculum, the Philippine government and policymakers are faced with the challenge of streamlining its current guidelines. To facilitate the development of existing policies and initiatives, this paper provides lenses on the status of the K-12 implementation in 
the country by evaluating the students' performance using a standardized test. The scholastic abilities test for adults (SATA) is used. The SATA is a standardized instrument that measures the cognitive and psychological factors thought to underlie academic competence as well as rate the skills closely associated with academic accomplishment. As such, it is well accepted in the literature that the reliability of the test is observed at $0.80-0.90$ on average (see [17]). The study is conducted in Cebu (Philippines) being one of the most highly urbanized areas in the country and having an increasing number of enrollments annually. Public schools offering senior (grade 12) high school programs are selected from three major cities in Cebu (Philippines)-Cebu City, Lapu-Lapu City, and Mandaue City. A stratified random sampling approach is performed on five strands of the K-12 program: (1) Science, Technology, Engineering, and Mathematics (STEM), (2) Accountancy and Business Management (ABM), (3) Humanities and Social Science (HUMSS), (4) Technical, Vocational, Livelihood (TVL), and (5) General Academic Strand (GAS). As a result, a total of 384 respondents were selected for evaluation. The total number of samples is composed of $38,41,48,70$, and 76, from STEM, ABM, HUMSS, TVL, and GAS, respectively.

3.2. Scholastic Abilities Test for Adults (SATA). The Scholastic Abilities Test for Adults (SATA) is a standardized instrument that measures the cognitive and psychological factors thought to underlie academic competence and the skills closely associated with academic accomplishment [17]. In SATA, six subtests are measured, namely, nonverbal reasoning $(\mathrm{NV})$, quantitative reasoning $(\mathrm{QR})$, reading vocabulary $(\mathrm{RV})$, reading comprehension (RC), mathematical capacity (MC), and mathematical applications (MA). The SATA measures the scholastic competence of persons from the ages of 16 through 70 [17]. The testing time takes 1-2 hours and can be administered individually or in groups. Subtest raw scores are then converted to estimated grade equivalents, standard scores $(M=10, S D=3)$, and percentiles [17]. Thus, the SATA's aptitude and achievement components can provide an aptitude-achievement discrepancy analysis needed for LD placement [17]. The SATA standard scores, composite quotients, and descriptions are summarized in Table 1.

\section{Results and Discussion}

With regard to the trend in the literature in measuring collegelevel readiness of students, the competencies of the respondents were tested using the SATA questionnaire with six subtests: (i) nonverbal reasoning (NV), (ii) quantitative reasoning (QR), (iii) reading vocabulary (RV), (iv) reading comprehension (RC), (v) mathematical capacity (MC), and (vi) mathematical applications (MA). As can be seen from the results shown in Table 1, no clear dominance in every competency can be attributed to a single SHS track. For instance, the STEM track dominates the NV and MC competencies, whereas the ABM track dominates the MA. Such results may imply the existence of an interaction between the track type and SATA subtest. As can be observed from Figure 1, the standardized scores of the track types exhibit some intersections which possibly manifest the presence of an interaction between the two factors (i.e., track type and SATA subtest) being considered. Moreover, it can also be observed from Figure 1 that the scores presented in Table 1 are divided into three parts based on Table 2. As such, the divisions' group scores are above average, on average, and below average.

Results show that respondents under STEM programs have above average competency in terms of NV, RV, and MC. Such a result is expected with STEM students due to the nature of the disciplines composing it, such as science, technology, engineering, and mathematics, which is largely dependent on mathematical competency, nonverbal ability, and problem-solving. Similarly, respondents under ABM programs exhibit above-average scores in RV, MC, and MA due to the fields that are primarily intertwined towards business. Following such results, it is interesting to point out how the ABM programs outperformed the STEM programs in terms of MA since STEM programs are also expected to obtain above-average performance in such a subtest due to their intensive exposure to problem-solving activities. Drawing inference in the context of the case scenario, several factors could be linked to such results. First, due to the attractiveness of the STEM track in terms of employment opportunities, it has become a melting pot of students with possibly widely varying scholastic abilities: (i) those predicted to fit the learning pace of STEM programs and (ii) those predicted to lag behind the learning pace of STEM programs. Subsequently, the lack of implementation of appropriate standards in application acceptance has played a critical role in magnifying such drawbacks. Such differences in their capabilities may have caused the observed mean of the STEM group to deviate from its expected mean. About such results, a more considerable variance is obtained by the STEM group in contrast to the ABM group, as shown in Table 1. Such an outcome could be a manifestation of a suboptimal clustering exhibited by the STEM group, implying that the STEM group is not as homogenous as any other group in the $\mathrm{K}-12$ clusters.

A general trend can be observed from the results shown in Table 2 and Figure 1. First, the ABM and STEM programs are on top of all the other programs in the overall test. Second, the GAS and HUMSS programs obtained average scores in most of the tests except for reading comprehension, whereas the TVL got belowaverage scores in most of the subsets. Despite the possible interaction between the track type and SATA subtest, it can be observed from the results that the interaction limits into select track types only. For instance, only the ABM and STEM programs have appeared to interact. The HUMSS, GAS, and TVL exhibit an interaction as well; however, they do not appear to interact with STEM. Such results show possible significant group differences between the track types, which would imply that some track types have higher academic performance than their counterparts. Such findings should be addressed as they might be pointing to several other drawbacks in the current K-12 programs. Since the inhomogeneity of the STEM track may have caused its score to lag behind its expected 
TABLE 1: SATA standardized table.

\begin{tabular}{lcc}
\hline Standard scores & Composite quotients & Description \\
\hline $17-20$ & $>130$ & Very superior (VS) \\
$15-16$ & $121-130$ & Superior (S) \\
$13-14$ & $111-120$ & Above average (AA) \\
$8-12$ & $90-110$ & Average (A) \\
$6-7$ & $80-89$ & Below average (BA) \\
$4-5$ & $70-79$ & Poor (P) \\
$1-3$ & $<70$ & Very poor (VP) \\
\hline
\end{tabular}

Note: this table summarizes the standardized scores, composite quotients, and description of the scores obtained from the respondents.

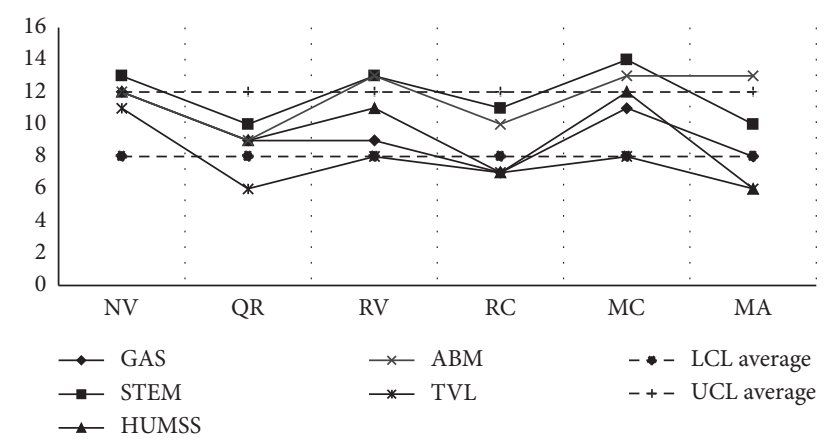

FIgURE 1: Mean interactions plot. The horizontal axis corresponds to each subtest of the SATA. The vertical axis corresponds to the average score obtained in each axis. Each line plot corresponds to each strand of the K-12 program in the Philippines. As a whole, the plot presents the interactions of the average score obtained by each $\mathrm{K}-12$ strand in each subtest.

TABLE 2: Resulting standardized SATA scores per track and SATA subtests.

\begin{tabular}{lcccccc}
\hline K-12 track & NV & QR & RV & RC & MC & MA \\
\hline STEM & 13 & 10 & 13 & 11 & 14 & 10 \\
GAS & 12 & 9 & 9 & 7 & 11 & 8 \\
HUMSS & 12 & 9 & 11 & 7 & 12 & 6 \\
ABM & 12 & 9 & 13 & 10 & 13 & 13 \\
TVL & 11 & 6 & 8 & 7 & 8 & 6 \\
\hline
\end{tabular}

Note: the subtests are nonverbal reasoning (NV), quantitative reasoning $(\mathrm{QR})$, reading vocabulary $(\mathrm{RV})$, reading comprehension (RC), mathematical capacity (MC), and mathematical applications (MA).

TABLE 3: SATA interpretation of resulting standardized test scores.

\begin{tabular}{lcccccc}
\hline Track & NV & QR & RV & RC & MC & MA \\
\hline STEM & AA & A & AA & A & AA & A \\
GAS & A & A & A & BA & A & A \\
HUMSS & A & A & A & BA & A & BA \\
ABM & A & A & AA & A & AA & AA \\
TVL & A & BA & A & BA & A & BA \\
\hline
\end{tabular}

Note: the row labels correspond to the K-12 strand of the K-12 program in the Philippines. The column labels correspond to the subtests of the SATA. The cell entries correspond to the linguistic equivalent of the scores obtained by each strand in each subtest. The entries represent in shorthand the following descriptions: very superior (VS), superior (S), above average $(\mathrm{AA})$, average $(\mathrm{A})$, below average $(\mathrm{BA})$, poor $(\mathrm{P})$, and very poor $(\mathrm{VP})$. performance, a possible implication could be that the current K-12 STEM programs may not prepare the students adequately for entering university-level STEM programs such as the physical sciences, technology, engineering, and mathematics. Similar arguments could also be applied to other programs as well.

Moreover, it can be inferred from Table 3 that among all K-12 tracks, only the STEM and ABM students obtained at least an average score in all subtests. However, all the other K-12 tracks obtained scores that are below average. In other words, despite the reforms made in the K-12 curriculum, many students may still be unprepared for higher education and obtaining overseas jobs, among others. Such concerns may become critical failure factors of the K-12 curriculum's implementation in the country. To address such drawbacks, the government must develop initiatives in reevaluating the current K-12 programs, for instance, developing learning outcomes that facilitate the basic competencies of students before choosing a track. In other words, before a student chooses a track, schools should already ensure that students have satisfied the basic competencies. Similarly, thorough studies in developing criteria needed to regroup the programs into highly significant clusters should also be conducted. In this way, students may be able to choose tracks that are more representative of their skills, talents, and interests. Likewise, the government and policymakers may introduce different learning outcomes for each K-12 track. In this way, performance indicators for each track may become more facilitated.

\section{Conclusion}

The introduction of the K-12 educational system in the Philippines has induced mixed remarks in the country. Several groups have strongly opposed the implementation of the curriculum primarily due to diverse opinions regarding the success of the curricular change. The competencies of the senior high school students in the Philippine $\mathrm{K}-12$ educational system has brought with it several concerns, primarily, with their mismatch with the expectation set for the program. As such, the challenges encountered in the K-12 transition are crucial to be addressed by developing strategies and initiatives in aligning the competencies of the K-12 students with their expected competencies. In this paper, SATA was administered to measure the competencies of the K-12 students in (a) STEM, (b) ABM, (c) HUMSS, (d) GAS, and (e) TVL, under six subtests of (i) nonverbal reasoning (NV), (ii) quantitative reasoning $(\mathrm{QR})$, (iii) reading vocabulary (RV), (iv) reading comprehension (RC), (v) mathematical capacity (MC), and (vi) mathematical applications (MA). A descriptive analysis was used to draw inferences on the data. Two factors were considered in the study: (i) K-12 program type and (ii) SATA subtest.

As a result, the STEM and the ABM groups obtained above-average scores in most of the subtests. The HUMSS and the GAS groups obtained average scores in most of the subtests. The TVL group obtained below-average scores in most of the subtests. Moreover, a potential interaction between the two factors was found; however, it appeared to be restricted only on track types. For instance, an interaction was observed to be divided into two classes: (i) interaction between STEM and ABM and (ii) interaction between HUMSS, GAS, and TVL. However, these two 
classes did not appear to exhibit potential interaction. In other words, the findings suggest that class (i) performed significantly better than class (ii) in all subtests. The paper evaluates the status of the K-12 curriculum in the Philippines using a standardized approach. The paper is the first to conduct such an assessment in the country. With the limited attention given by scholars regarding the status of the K-12 curriculum implementation in the Philippines, the results of the study would be significant to the current literature. By evaluating the performance of the K-12 students in the Philippines, scholars would have insights on how the K-12 educational system works in the Philippines' perspective. Moreover, the findings can be used to draw out potential strategies and initiatives by stakeholders in the Philippines as well as in other developing countries. For future works, several methodological approaches can be adopted, such as structural modeling, to determine possible interrelationships that may have been exhibited by the factors affecting the dynamics of the K-12 educational system.

\section{Data Availability}

The data used to support the findings of this study are included in the manuscript.

\section{Conflicts of Interest}

The authors declare that they have no conflicts of interest.

\section{References}

[1] G. Adarlo and L. Jackson, "For whom is K-12 education: a critical look into twenty-first century educational policy and curriculum in the Philippines," in Proceedings of the Educating for the 21st Century, pp. 207-223, Springer, Singapore, 2017.

[2] C. Glavin, "Education in the United States | K12 academics," 2014, http://www.k12academics.com.

[3] H. Yazdi, "Education and literacy in Afghanistan: lessons of history and prospects for change," Monitor: Journal of International Studies, vol. 14, no. 1, pp. 30-50, 2008.

[4] M. M. Hynes, C. Mathis, S. Purzer, A. Rynearson, and E. Siverling, "A systematic review of research in P-12 engineering education from 2000-2015," International Journal of Engineering Education, vol. 33, no. 1, pp. 453-462, 2017.

[5] D. Beveridge, M. McKenzie, K. Aikens, and K. Strobbe, "A national census of sustainability in $\mathrm{K}-12$ education policy: implications for international monitoring, evaluation, and research," Canadian Journal of Educational Administration and Policy, vol. 188, pp. 36-52, 2019.

[6] L. Johnson, D. Liu, R. Huang et al., NMC Technology Outlook: Chinese K-12 Education, The New Media Consortium, Austin, TX, USA, 2016.

[7] Y. J. Joo, K. Y. Lim, and N. H. Kim, "The effects of secondary teachers' technostress on the intention to use technology in South Korea," Computers \& Education, vol. 95, pp. 114-122, 2016.

[8] S. Kucuk, M. Aydemir, G. Yildirim, O. Arpacik, and Y. Goktas, "Educational technology research trends in Turkey from 1990 to 2011," Computers \& Education, vol. 68, pp. 42-50, 2013.

[9] M. Okabe, Where Does Philippine Education Go?: the "K to 12" Program and Reform of Philippine Basic Education, Institute of Developing Economies, Chiba, Japan, 2013.

[10] J. G. Rivera, "Articulating the foundations of Philippine K to 12 curriculum: learner-centeredness," AsTEN Journal of Teacher Education, vol. 2, no. 1, 2017.

[11] J. Barrot, "Exploring the implementation of communicative language teaching in the Philippines: a tertiary teachers' perspective," Advanced Science Letters, vol. 24, no. 4, pp. 2284-2287, 2018.

[12] N. J. C. Trance and L. A. M. L. Trance, "Embracing the K-12 curriculum: accounts of Philippine teachers and students," in Proceedings of the Journal of Physics: Conference Series, vol. 1254, no. 1, November 2019, Article ID 012031.

[13] F. S. Relucio and T. D. Palaoag, "Sentiment analysis on educational posts from social media," in Proceedings of the 9th International Conference on E-Education, E-Business, E-Management and E-Learning, pp. 99-102, San Diego, CA, USA, January 2018.

[14] J. R. Badger and J. Mellanby, "Revealing hidden talents: the development, use, and benefit of VESPARCH," British Journal of Educational Psychology, vol. 88, no. 3, pp. 380-395, 2018.

[15] F. L. Tseng, C. Chang-Hung, C. Shih-Yu, and C. Ming-Chiu, "Development and implementation of a standardized junior high school classroom literacy assessment: English reading comprehension as an example," Jiaoyu Kexue Yanjiu Qikan, vol. 63, no. 4, p. 119, 2018.

[16] J. Bietenbeck, S. Ericsson, and F. M. Wamalwa, "Preschool attendance, schooling, and cognitive skills in East Africa," Economics of Education Review, vol. 73, Article ID 101909, 2019.

[17] B. R. Bryant, J. R. Palton, and C. Dunn, SATA-Scholastic Abilities Test for Adults, Pro-Ed, Austin, TX, USA, 1991.

[18] J. R. G. Albert, "What do statistics say about basic education in the Philippines?" PIDS Policy Notes, vol. 2016, pp. 1-9, 2016.

[19] Department of Education (DepEd), PISA 2018-National Report of the Philippines, OECD, Paris, France, 2019.

[20] I. V. S. Mullis, M. O. Martin, E. J. Gonzalez, and S. J. Chrostowski, "TIMMS 2003: international science report,” 2004, http://timssandpirls.bc.edu/PDF/t03_download/ T03INTLMATRPT.pdf.

[21] M. O. Martin, I. V. S. Mullis, E. J. Gonzalez, and S. J. Chrostowski, "TIMMS 2003: international science report,” 2004, http://timssandpirls.bc.edu/PDF/t03_download/ T03INTLSCIRPT.pdf.

[22] I. V. S. Mullis, M. O. Martin, E. J. Gonzalez et al., "TIMMS 1999: international mathematics report," 2000, http:// timssandpirls.bc.edu/timss1999i/pdf/T99i_Math_All.pdf.

[23] M. O. Martin, I. V. S. Mullis, E. J. Gonzalez et al., "TIMMS 1999: international science report," 2000, http://timssandpirls. bc.edu/timss1999i/pdf/T99i_Sci_All.pdf.

[24] M. R. S. Sergio, "K-12 education reform: problems and prospects,” Gibon, vol. 9, pp. 70-80, 2011.

[25] A. Krouska, C. Troussas, and M. Virvou, "SN-Learning: an exploratory study beyond e-learning and evaluation of its applications using EV-SNL framework," Journal of Computer Assisted Learning, vol. 35, no. 2, pp. 168-177, 2019.

[26] A. Krouska, C. Troussas, and M. Virvou, "A literature review of social networking- based learning systems using a novel ISO-based framework," Intelligent Decision Technologies, vol. 13, no. 1, pp. 23-39, 2019.

[27] C. Troussas, A. Krouska, and C. Sgouropoulou, "Collaboration and fuzzy-modeled personalization for mobile game- 
based learning in higher education," Computers \& Education, vol. 144, Article ID 103698, 2020.

[28] C. Troussas, A. Krouska, and M. Virvou, "Injecting intelligence into learning management systems: the case of adaptive grainsize instruction," in Proceedings of the 2019 10th International Conference on Information, Intelligence, Systems and Applications (IISA), IEEE, Patras, Greece, pp. 1-6, July 2019.

[29] A. Krouska, C. Troussas, and M. Virvou, "Comparing LMS and CMS platforms supporting social e-learning in higher education," in Proceedings of the 2017 8th International Conference on Information, Intelligence, Systems \& Applications (IISA), IEEE, Patras, Greece, pp. 1-6, August 2017.

[30] R. V. Nuncio, M. M. Arcinas, R. I. G. Lucas, J. V. Q. Alontaga, S. G. T. Neri, and J. M. Carpena, "An E-learning outreach program for public schools: findings and lessons learned based on a pilot program in Makati city and Cabuyao city, Laguna, Philippines," Evaluation and Program Planning, vol. 82, Article ID 101846, 2020.

[31] J. L. Espiritu and K. Budhrani, "Cultivating an e-learning culture," in Proceedings of the National Conference on Technology in Education, SMX Mall of Asia, Manila, Philippines, 2016.

[32] L. S. V. Castillo, "Call of duty: a case study of ICT integration in Philippine provincial public schools in san isidro davao oriental post K-12 implementation," JPAIR Multidisciplinary Research, vol. 30, pp. 1-16, 2017.

[33] M. Tam, "Measuring quality and performance in higher education," Quality in Higher Education, vol. 7, no. 1, pp. 47-54, 2001.

[34] J. Johnes and J. Taylor, Performance Indicators in Higher Education, SRHE \& Open University Press, Buckingham, UK, 1990.

[35] A. S. Horn, O. G. Horner, and G. Lee, "Measuring the effectiveness of two-year colleges: a comparison of raw and value-added performance indicators," Studies in Higher Education, vol. 44, no. 1, pp. 151-169, 2019.

[36] B. Srisakda, S. Sujiva, and S. Pasiphol, "Development of indicators of learner's key competencies based on the basic education core curriculum," Procedia-Social and Behavioral Sciences, vol. 217, pp. 239-248, 2016.

[37] T. K. Man, A. C. Lee-Yen, A. M. Radzi, and R. Gong, Behind the Blackboard: How Basic Indicators Mask Gaps in Quality of Education, Khazanah Research Institute, Kuala Lumpur, Malaysia, 2019.

[38] C. Junio-Sabio, M. M. Manalo, M. M. Manalo, and F. G. Vigonte, "Determining students' learning outcomes in basic education: a proposed CPD for teachers," International Journal of Information and Education Technology, vol. 10, no. 1, pp. 62-66, 2020.

[39] H. D. Bonsu, "A comparative analysis of academic performance of public and private junior high schools in the basic education certificate in Sekondi/Takoradi," European Journal of Basic and Applied Sciences, vol. 3, no. 1, pp. 21-32, 2016.

[40] J. O. Wao, K. B. Bibins, R. Hunt, M. Eng, R. Ries, and S. Schattner, "SAT and ACT scores as predictors of undergraduate GPA scores of construction science and management students," in Proceedings of the 53rd ASC Annual International Conferenc, Seattle, WA, USA, April 2017.

[41] M. Curabay, "Meta-analysis of the predictive validity of scholastic aptitude test (SAT) and American college testing (ACT) scores for college GPA," M.S. thesis, electronic theses and dissertations, University of Denver, Denver, CO, USA, 2016.

[42] T. Coyle, A. Snyder, D. Pillow, and P. Kochunov, "SAT predicts GPA better for high ability subjects: implications for Spearman's law of diminishing returns," Personality and Individual Differences, vol. 50, no. 4, pp. 470-474, 2011. 